\title{
Article \\ Paclitaxel Induces Epidermal Molecular Changes and Produces Subclinical Alterations in the Skin of Gynecological Cancer Patients
}

\author{
Paula Montero ${ }^{1, *,+}$, Martín Pérez-Leal ${ }^{2,+}{ }^{\mathbb{D}}$, Jose Alejandro Pérez-Fidalgo ${ }^{3,4,5}$, Celia Sanz ${ }^{1,6}$, Cristina Estornut ${ }^{1}$, \\ Inés Roger ${ }^{1,7}$, Javier Milara ${ }^{1,7,8}$, Andrés Cervantes ${ }^{5}$ (D) and Julio Cortijo ${ }^{1,7,9}$
}

Citation: Montero, P.; Pérez-Leal, M.; Pérez-Fidalgo, J.A.; Sanz, C.;

Estornut, C.; Roger, I.; Milara, J.; Cervantes, A.; Cortijo, J. Paclitaxel Induces Epidermal Molecular Changes and Produces Subclinical Alterations in the Skin of Gynecological Cancer Patients. Cancers 2022, 14, 1146. https:// doi.org/10.3390/cancers14051146

Academic Editors: Georg T. Wondrak and Jan B. Vermorken

Received: 9 December 2021 Accepted: 22 February 2022 Published: 23 February 2022

Publisher's Note: MDPI stays neutral with regard to jurisdictional claims in published maps and institutional affiliations.

Copyright: () 2022 by the authors Licensee MDPI, Basel, Switzerland. This article is an open access article distributed under the terms and conditions of the Creative Commons Attribution (CC BY) license (https:// creativecommons.org/licenses/by/ $4.0 /)$.
1 Department of Pharmacology, Faculty of Medicine, University of Valencia, 46010 Valencia, Spain; celia.sanz@uv.es (C.S.); cristina.estornut@uv.es (C.E.); irola3@alumni.uv.es (I.R.); milara_jav@gva.es (J.M.); julio.cortijo@uv.es (J.C.)

2 Faculty of Health Sciences, Universidad Europea de Valencia, 46010 Valencia, Spain; martin.perez@universidadeuropea.es

3 Department of Medical Oncology, Hospital Clínico Universitario de Valencia, 46010 Valencia, Spain; jopefi@uv.es

4 Biomedical Research Networking Centre on Cancer (CIBERONC), Health Institute Carlos III, 28029 Madrid, Spain

5 INCLIVA Biomedical Research Institute, 46010 Valencia, Spain; andres.cervantes@uv.es

6 Health Sciences, Pre-Departmental Section of Medicine, Jaume I University of Castellón de la Plana, 12071 Castellón, Spain

7 Biomedical Research Networking Centre on Respiratory Diseases (CIBERES), Health Institute Carlos III, 28029 Madrid, Spain

8 Pharmacy Unit, University General Hospital Consortium, 46014 Valencia, Spain

9 Research and Teaching Unit, University General Hospital Consortium, 46014 Valencia, Spain

* Correspondence: paula.montero@uv.es; Tel.: +34-963864631

+ These authors contributed equally to this work.

Simple Summary: Skin toxicity is one of paclitaxel's adverse effects. However, its real impact on the skin could be underestimated as these alterations can also appear asymptomatic. We have observed that paclitaxel modifies gene and protein expression of skin markers in a 3D epidermis model, and impairs physical, physiological, and biomechanical properties of the skin in gynecologic cancer patients. These subclinical alterations might be avoided by using prophylactic measures during treatment to prevent possible future adverse reactions.

Abstract: Background: Paclitaxel is a microtubule-stabilizing chemotherapeutic agent. Despite its widespread use, it damages healthy tissues such as skin. The goal of this study was to prove that the real impact of paclitaxel-induced skin toxicity could be underestimated because the adverse events might appear asymptomatic. Methods: Gynecological cancer patients were recruited. Skin parameters measurements were taken after three and six paclitaxel cycles. Measurements were conducted using specific probes which measure hydration, transepidermal water loss (TEWL), sebum, elasticity and firmness, erythema, roughness, smoothness, skin thickness, and desquamation levels. Further, a 3D epidermis model was incubated with paclitaxel to analyze gene and protein expression of aquaporin 3 , collagen type 1, elastin, and fibronectin. Results: Paclitaxel induced alterations in the skin parameters with no visible clinical manifestations. Gynecological cancer patients under paclitaxel treatment had a decrease in hydration, TEWL, sebum, elasticity, and thickness of the skin, while erythema, roughness, and desquamation were increased. The molecular markers, related to hydration and the support of the skin layers, and analyzed in the 3D epidermis model, were decreased. Conclusions: Results suggest that paclitaxel modifies gene and protein expression of skin-related molecular markers, and impairs different physical, physiological, and biomechanical properties of the skin of cancer patients at a subclinical level.

Keywords: paclitaxel; skin alterations; epidermis; 3D epidermis model 


\section{Introduction}

Taxanes are chemotherapeutic agents that produce antitumor activity by causing stabilization of microtubules, thereby inhibiting cell cycle progression [1]. Paclitaxel (PTX) is the prototype of the taxane family of antitumor compounds and binds to the $\beta$-tubulin subunit in the microtubule, leading to its stabilization and increasing microtubule polymerization [2]. This unique mechanism of action differentiates paclitaxel from other antimicrotubule agents such as vinca alkaloids or colchicine, which inhibit tubulin polymerization. The microtubules formed in the presence of paclitaxel are so stable that they cause cell death by disrupting the normal microtubule dynamics required for cell division and interphase processes [3]. The consequent arrest of the cell cycle has been considered as the cause of paclitaxel-induced cytotoxicity. However, the signaling pathways that lead to apoptosis are not well understood. Recent discoveries indicate that paclitaxel initiates apoptosis through multiple mechanisms [4].

In 1992, paclitaxel was approved by the US Food and Drug Administration (FDA) for the treatment of ovarian cancer. In 1996, a study of the Gynecologic Oncology Group (GOG) showed that paclitaxel-cisplatin was superior in terms of survival to the cyclophosphamidecisplatin regimen as upfront therapy in stage III-IV ovarian cancer patients [5]. These results were confirmed by the European-Canadian Intergroup study [6]. These data justified the use of paclitaxel and platinum combination, and the treatment has become the standard of care in the first line. In the platinum-resistant setting, weekly paclitaxel has been considered one of the recommended regimens [7]. In endometrial and cervical cancer, paclitaxel in combination with platinum has also become part of the standard regimens in the first-line treatment. From this point, paclitaxel has been also used in the treatment of other cancers including colorectal and breast cancer, head and neck cancers, small-cell and non-small-cell lung cancers, and AIDS-related Kaposi Sarcoma [8].

Although taxanes are tolerable and manageable, their toxic profile includes a wide number of adverse events. Hematological, cardiologic, and neurologic toxicities are very common in taxane-containing regimens [9]. Neutropenia is described amongst the principal toxic effects of PTX and is dose-limiting [10]. Peripheral neuropathy, another dosedependent side effect, is found in $60-70 \%$ of chemotherapy patients and is characterized by sensory symptoms, such as numbness and paresthesia [11]. One of the most frequent adverse events is taxane-induced dermatologic toxicity, which has been reported in up to $89 \%$ of patients [12]. The spectrum of cutaneous reactions to paclitaxel includes alopecia, hypersensitivity reactions such as erythema and urticaria, nail changes, and radiation recall dermatitis. Less common effects such as acral erythema, erythema multiforme, pustular dermatitis, and scleroderma-like changes have also been described [12,13]. Generally, the adverse effects on the skin are mild to moderate in severity and self-limiting. Consequently, they are usually dose-dependent and sometimes require dose reductions, interruptions, or termination of the taxane chemotherapy [14].

There are scarce data regarding the mechanisms that lead to these toxic effects and most remain not understood. Moreover, the real impact of the taxane-induced skin toxicity could be underestimated as the skin adverse events are usually under-reported or paucisymptomatic [14]. The available data in vivo are limited to case reports and oncology studies, and usually describe events happening to symptomatic patients. There is no information regarding the impact of taxanes on the skin in patients without cutaneous symptoms. However, a direct cytotoxic effect of chemotherapy on basal keratinocytes has been proposed; histology from skin biopsies of PTX treated patients have shown alterations in keratinocytes when some cutaneous events occur [15-17]. Further, studies in vitro have described that paclitaxel induces a cytotoxic response in transformed HaCat keratinocytes [18] and produces epithelial damage in zebrafish models [19,20]. Further, our previous results showed that paclitaxel impacts on the expression of proteins related to angiogenesis, elasticity, inflammation, and senescence in human keratinocytes [21].

Of note, studies on undifferentiated keratinocyte monolayer cultures can lack some of the physiological functions of the stratified keratinocyte epithelium and could misinterpret 
the results obtained in preclinical studies. Thereby, various three-dimensional (3D) skin equivalents reproducing in vivo conditions have been developed for pharmacologic and toxicologic in vitro testing as an alternative to animal models [22,23]. One of these models is characterized by the growth of keratinocytes on a feeder layer of lethally irradiated 3T3 fibroblasts. The feeder layer supports and maintains keratinocyte colony growth and stratification $[24,25]$, producing a 3D model that is compatible with autologous and allogenic transplantation [26,27].

In this study, we aimed to overcome the lack of investigation regarding subclinical alterations induced by PTX. Therefore, we analyzed PTX-induced subclinical skin alterations by measuring different biomechanical properties of the skin in oncologic patients. Secondly, we reconstructed a 3D epidermis cell model to mimic a healthy epidermis and evaluate the effects of paclitaxel in some of the molecular markers associated with skin homeostasis. The results obtained will help understand asymptomatic skin alterations to prevent possible future skin adverse effects.

\section{Materials and Methods}

\subsection{Patients}

This project was approved by the Research Ethics Committee of Valencia University Clinical Hospital and further authorized by the Valencian Regional Ministry of Health. Informed consent was obtained from each participant before starting the study. Twenty cancer patients and 20 healthy volunteers were recruited from the oncology service at Valencia University Clinical Hospital. The patients' clinical features can be found in Table 1. Inclusion criteria for the control group comprised being Caucasian females aged 40-70 years old. Exclusion criteria included having an acute illness, skin pathologies, being pregnant, or breastfeeding. The inclusion criteria for cancer patients included: (1) being over 18 years old; (2) having a clinical diagnosis of gynecological cancer (ovarian, cervix or endometrium cancer at any stage of the International Federation of Gynecology and Obstetrics (FIGO) classification); (3) having indication for treatment with taxanes; (4) being treated for the first time or in relapse; (5) having adequate kidney, liver, and hematological functions before treatment; or (6) having PTX prescription on a 3 week schedule in combination or PTX in a weekly schedule either in monotherapy or in combination. Exclusion criteria comprised (1) having known chronic or rheumatologic skin disease; (2) being under corticosteroid treatment 2 weeks before admission to the study; (3) acute illness; (4) being pregnant or breastfeeding; or (5) having visible skin adverse effects. During the study, patients were not allowed to use cosmetic treatments.

Table 1. Patients' clinical features.

\begin{tabular}{|c|c|c|c|c|c|c|c|c|}
\hline $\mathbf{N}^{\mathbf{o}}$ & Age & Location & Tumor Subtype & Grade & $\begin{array}{c}\text { FIGO } \\
\text { Classification }\end{array}$ & Strategy & Treatment & $\begin{array}{c}\text { Previous } \\
\text { Taxane }\end{array}$ \\
\hline 1 & 63 & Ovary & Serous carcinoma & High & III & Pt-sensitive relapse & $\begin{array}{c}\text { Paclitaxel + Carboplatin + } \\
\text { Bevacizumab }\end{array}$ & yes \\
\hline 2 & 60 & Endometrium & Carcinosarcoma & High & IV & $\begin{array}{l}\text { 2nd } \\
\text { line }\end{array}$ & Paclitaxel + Carboplatin & yes \\
\hline 3 & 62 & Ovary & Serous carcinoma & High & IV & Pt-resistant relapse & $\begin{array}{l}\text { weekly Paclitaxel + } \\
\text { Bevacizumab }\end{array}$ & yes \\
\hline 4 & 63 & Ovary & Serous carcinoma & High & III & Pt-sensitive relapse & Paclitaxel + Carboplatin & yes \\
\hline 5 & 57 & Ovary & Serous carcinoma & High & III & Pt-resistant relapse & $\begin{array}{c}\text { weekly Paclitaxel + } \\
\text { Bevacizumab }\end{array}$ & yes \\
\hline 6 & 55 & Endometrium & $\begin{array}{c}\text { Endometrioid } \\
\text { adenocarcinoma }\end{array}$ & Grade 3 & IV & $\begin{array}{l}\text { 2nd } \\
\text { line }\end{array}$ & weekly Paclitaxel & yes \\
\hline 7 & 47 & Ovary & $\begin{array}{l}\text { Clear cell } \\
\text { carcinoma }\end{array}$ & High & III & Pt-resistant relapse & weekly Paclitaxel & yes \\
\hline 8 & 64 & Endometrium & Serous carcinoma & High & III & $\begin{array}{c}\text { 1st } \\
\text { tline }\end{array}$ & Paclitaxel + Carboplatin & yes \\
\hline
\end{tabular}


Table 1. Cont.

\begin{tabular}{|c|c|c|c|c|c|c|c|c|}
\hline $\mathbf{N}^{\mathbf{o}}$ & Age & Location & Tumor Subtype & Grade & $\begin{array}{c}\text { FIGO } \\
\text { Classification }\end{array}$ & Strategy & Treatment & $\begin{array}{c}\text { Previous } \\
\text { Taxane }\end{array}$ \\
\hline 9 & 55 & Ovary & Serous carcinoma & High & II & Pt-sensitive relapse & Paclitaxel + Carboplatin & yes \\
\hline 10 & 82 & Endometrium & $\begin{array}{c}\text { Endometrioid } \\
\text { adenocarcinoma }\end{array}$ & Grade 3 & III & Pt-sensitive relapse & Paclitaxel + Carboplatin & yes \\
\hline 11 & 57 & Ovary & Serous carcinoma & High & III & adjuvant & Paclitaxel + Carboplatin & no \\
\hline 12 & 32 & Ovary & $\begin{array}{l}\text { Undifferentiated } \\
\text { adenocarcinoma }\end{array}$ & High & IV & Pt-resistant relapse & weekly Paclitaxel & yes \\
\hline 13 & 52 & Ovary & $\begin{array}{c}\text { Endometrioid } \\
\text { adenocarcinoma }\end{array}$ & Grade 2 & I & Adjuvant & Paclitaxel + Carboplatin & no \\
\hline 14 & 77 & Cervix & $\begin{array}{l}\text { Epidermoid } \\
\text { carcinoma }\end{array}$ & NS & IV & $\begin{array}{l}\text { 2nd } \\
\text { line }\end{array}$ & weekly Paclitaxel & yes \\
\hline 15 & 45 & Endometrium & Carcinosarcoma & High & $\mathrm{I}$ & $\begin{array}{l}1 \text { st } \\
\text { line }\end{array}$ & Paclitaxel + Carboplatin & no \\
\hline 16 & 83 & Ovary & Serous carcinoma & High & III & Neoadjuvant & Paclitaxel + Carboplatin & no \\
\hline 17 & 72 & Ovary & Serous carcinoma & High & III & Pt-resistant relapse & weekly Paclitaxel & yes \\
\hline 18 & 71 & Endometrium & $\begin{array}{c}\text { Endometrioid } \\
\text { adenocarcinoma }\end{array}$ & Grade 3 & I & Adjuvant & Paclitaxel + Carboplatin & no \\
\hline 19 & 74 & Ovary & Serous carcinoma & High & III & Pt-resistant relapse & weekly Paclitaxel & yes \\
\hline 20 & 61 & Ovary & $\begin{array}{l}\text { Clear cell } \\
\text { carcinoma }\end{array}$ & High & I & Adjuvant & Paclitaxel + Carboplatin & no \\
\hline
\end{tabular}

Grade: Depends on the cancer aggressiveness-for endometrial and endometrioid-type ovarian tumors, grades are classified according to the classic system from 1 to 3 . For ovarian tumors, the current high-grade versus low-grade grading system is shown. Stage: International Federation of Gynecology and Obstetrics (FIGO) classification scale from I to IV. Strategy: For endometrial and cervical tumors, it is reported whether it was for localized disease (adjuvant) or the number of chemotherapy lines for advanced disease (1st line or 2nd line). For ovarian tumors, it is reported if the strategy was for localized disease (adjuvant or neoadjuvant) or advanced disease according to previous platinum sensitivity (platinum-sensitive or platinum-resistant). Refractory cancers were categorized as platinum-resistant. Treatment: weekly paclitaxel $\left(80 \mathrm{mg} / \mathrm{m}^{2}\right)$ was administered at days 1,8 , and 15 every 21 days. Three weekly paclitaxel $\left(175 \mathrm{mg} / \mathrm{m}^{2}\right)+$ carboplatin (AUC5) was administered in day 1 every 21 days. Abbreviation: NS: not specified; Pt-sensitive: platinum-sensitive; Pt-resistant: platinum-resistant.

\subsection{Skin Parameters Measurements}

Skin parameter measurements were performed in three visits: before treatment (T1), during treatment after 3 chemotherapy cycles (T2), and at the end of treatment after 6 chemotherapy cycles (T3). The measurements were taken using specific probes following the measurement guidelines [28-30]. All probes were purchased from Courage-Khazaka Electronic (Cologne, Germany).

Corneometer CM 825 ${ }^{\circledR}$ (Courage-Khazaka Electronic, Cologne, Germany) was used to obtain cheekbone and forearm hydration values. This probe measures the electrical capacity of the stratum corneum, based on the linear dependency of the electrical property of the epidermis to its hydration. The results are displayed in arbitrary units [28].

Tewameter TM $300^{\circledR}$ (Courage-Khazaka Electronic, Cologne, Germany) was used to provide cheekbone and forearm values of transepidermal water loss (TEWL). The probe measures the vapor pressure and calculates TEWL from the difference between two measurement points using Fick's law of diffusion. It displays the results in grams per hour per square meter $\left(\mathrm{g} / \mathrm{hm}^{2}\right)$ [31].

Sebumeter SM $815^{\circledR}$ (Courage-Khazaka Electronic, Cologne, Germany) was used to obtain the forehead sebum value. The probe determines the translucency of a special tape, which becomes transparent after contact with sebum on the skin surface and displays the sebum values in $\mu \mathrm{g}$ per square centimeter $\left(\mu \mathrm{g} / \mathrm{cm}^{2}\right)$ [32].

Mexameter MX $18^{\circledR}$ (Courage-Khazaka Electronic, Cologne, Germany) was used to determine the forearm erythema based on tissue's narrow wavelength light absorption. Results are displayed as erythema index in arbitrary units [29]. 
Skin elasticity and firmness were assessed in the cheekbone with Cutometer ${ }^{\circledR}$ MPA 580. This probe suctions skin and gives a series of $\mathrm{R}$ values. The ones that provide more information about elasticity and firmness are R0, R2, R5, and R7. R0 expresses the maximum width of skin and is given in $\mathrm{mm}$. $\mathrm{R} 2$ represents the ratio between the maximum width of the skin and its ability to return to its original state after suction (Ua/Uf). R5 represents the ratio between the elasticity of the suction phase and the elasticity of the relaxation phase (Ur/Ue). R7 represents the elastic recovery ratio (Ur/Uf). The closer R2, R5, and R7 are to 1 , the greater the elasticity.

Skin smoothness and roughness were assayed in the cheekbone by Visioscan ${ }^{\circledR}$ (CourageKhazaka Electronic, Cologne, Germany). The device takes grayscale photographs to study the epidermis surface and analyzes the obtained images, where white and bright gray are associated with a bad condition of the skin. The software uses the images to determine the skin topography parameters SELS (surface evaluation of the living skin) [33]. The given parameters are smoothness (Sesm) and roughness (Ser) and are expressed in arbitrary units. Low values of Sesm inform about smoother skin, while high values of Ser imply rougher skin [34].

Visioscan ${ }^{\circledR}$ was also combined with the Corneofix ${ }^{\circledR}$ (Courage-Khazaka Electronic, Cologne, Germany) technique to obtain the skin desquamation index on the forehead. Corneofix ${ }^{\circledR}$ is a tape that adheres to the skin and collects corneocytes. Then, the tape is placed on the Visioscan ${ }^{\circledR}$ probe which takes an image and processes it with a determined color grading, depending on the desquamation level. The color scale ranges from cool to warm colors. The software also analyzes the number, size, and thickness of the attached corneocytes to the Corneofix ${ }^{\circledR}$ tape and gives the desquamation percentage.

Finally, Ultrascan ${ }^{\circledR}$ UC22(Courage-Khazaka Electronic, Cologne, Germany) was used to analyze the thickness of the different layers of the skin on the forearm. The probe takes an ultrasound image of the skin.

All measurements were taken under controlled conditions. Temperature was maintained at $22 \pm 2{ }^{\circ} \mathrm{C}$ and relative humidity between $40 \%$ and $60 \%$. Measurements were taken after patients remained in a $30 \mathrm{~min}$ acclimatization period in the same atmospheric conditions.

\subsection{Epidermis Cell Model Reconstruction}

Three-dimensional epidermis cell models were reconstructed using the BALB/3T3 feeder-layer technique adapted from Mak et al. [35] and Arnette et al. [24]. In brief, $10^{6}$ BALB/3T3 fibroblasts (Lonza, Basel, Switzerland) were seeded on collagen-coated Millicell inserts (Millicell-CM 12 mm, transparent Biophore Membrane; Millipore Corp., Bedford, MA, USA) and placed into 6-well plates (Corning Incorporated, Corning, NY, USA). Fibroblasts were cultured for 2 days in $1 \mathrm{~mL}$ Dulbecco's Modified Eagle Medium (DMEM, high glucose; Gibco, Waltham, MA, USA) supplemented with $10 \%$ fetal calf serum (FCS, Gibco, Waltham, MA, USA) and added to the apical and dorsal side of the insert. When fibroblasts reached $60-70 \%$ confluence, the monolayer was irradiated with UV light at $0.048 \mathrm{~mW}$ for $1 \mathrm{~h}$ with UVACUBE 400 (Honle UV Technology, Gräfelfing, Germany) to establish the feeder layer. Then, primary adult epidermal keratinocytes (192627, Lonza, Basel, Switzerland) were seeded at a density of $0.5 \times 10^{6}$ cells $/ \mathrm{cm}^{2}$. Cultures were grown at $37{ }^{\circ} \mathrm{C}$ and $95 \%$ air $/ 5 \% \mathrm{CO}_{2}$ until approximately $60 \%$ confluency and then were switched to Keratinocyte Growth Medium (KGM-Gold ${ }^{\mathrm{TM}}$, Lonza, Basel, Switzerland) supplemented with KGM-Gold SingleQuot Kit (Lonza) until confluent. Confluent cultures were raised to the air-liquid interface and cultured for 21 days until epidermal stratification was achieved. To validate the stratification, histological analysis was performed after 21 days. The reconstructed epidermis tissues were fixed with 10\% formalin solution, dehydrated, and embedded in paraffin. Six-micrometer-thick sections were cut and stained with hematoxylin-eosin. Random photographs were taken of each sample with a Leica DM6000B microscope (Leica Biosystems, Wetzlar, Germany). 


\subsection{Real Time RT-qPCR}

The 3D epidermal cell models were incubated for $24 \mathrm{~h}$ with PTX within the clinically achievable plasma concentrations of $0.3,3$, and $30 \mu \mathrm{M}$ [36-38]. After incubation, total RNA was extracted using TRIzol ${ }^{\circledR}$ Reagent (Invitrogen, Thermo Fisher Scientific, Waltham, MA, USA) following the manufacturer's instructions. Reverse transcription was performed in 500 ng of total RNA with a TaqMan reverse transcription reagents kit (Applied Biosystems, Thermo Fisher Scientific, Waltham, MA, USA). cDNA was amplified with specific primers and probes predesigned by Applied Biosystems for aquaporin 3 (AQP3) (Hs00185020_m1), collagen type 1 (COL1) (Hs00164004_m1), elastin (ELN) (Hs00355783_m1), and fibronectin (FN1) (Hs01549976_m1) in a QuantStudio ${ }^{\text {TM }} 5$ Real-Time PCR System, using universal master mix (Applied Biosystems, Thermo Fisher Scientific, Waltham, WA, USA). Expression of the target gene was expressed as the fold increase or decrease relative to the expression of $\beta$-actin (Hs01060665_g1) as an endogenous control. The mean value of the replicates for each sample was calculated and expressed as the cycle threshold $(\mathrm{Ct})$. Gene expression level was calculated as the difference $(\Delta \mathrm{Ct})$ between the $\mathrm{Ct}$ value of the target gene and the $C t$ value of $\beta$-actin. The fold changes in the target gene mRNA levels were designated $2^{-\Delta \mathrm{Ct}}$.

\subsection{Western Blotting Analysis}

The 3D epidermal cell models were incubated for $24 \mathrm{~h}$ with different PTX concentrations $(0.3,3$, and $30 \mu \mathrm{M})$. After incubation, protein extraction was performed incubating samples with lysis buffer (1M HEPES, $4 \mathrm{M} \mathrm{NaCl}$, 0.5 M EDTA, 0.1 M EGTA) supplemented with a protease inhibitory cocktail complete ${ }^{\mathrm{TM}}$ and phenyl-methyl-sulfonyl fluoride (PMSF) (Roche Diagnostics, Indianapolis, IN, USA). Total protein concentration was quantified using the BCA Protein Assay Kit (Thermo Fisher Scientific, Waltham, MA, USA). Protein electrophoresis was performed to separate proteins according to their molecular weight. Twelve micrograms of denatured proteins along with Rainbow ${ }^{\mathrm{TM}}$ molecular weight marker (Sigma-Aldrich, Saint Louis, MO, USA) were loaded into Mini-PROTEAN ${ }^{\circledR}$ polyacrylamide gels TGX ${ }^{\mathrm{TM}}$ (Bio-Rad, Herts, UK) by application of $100 \mathrm{~V}$ during $1 \mathrm{~h}$. Proteins were transferred from the gel to a nitrocellulose membrane Trans-Blot ${ }^{\circledR}$ Turbo $^{\mathrm{TM}}$ Transfer Pack, using the Trans-Blot ${ }^{\circledR}$ Turbo ${ }^{\text {TM }}$ Transfer System (Bio-Rad Laboratories, Herts, UK). Then, membranes were incubated with $5 \%$ bovine serum albumin (BSA) for $2 \mathrm{~h}$ and labeled overnight at $4{ }^{\circ} \mathrm{C}$, with various primary antibodies. The secondary antibody was incubated for $1 \mathrm{~h}$ at room temperature. The primary antibodies used were the following: AQP3 (ab125219, Abcam, Cambridge, UK); COL1A (PA5-95137, Thermo Fisher Scientific, Waltham, MA, USA); FN1 (PA5-29578, Thermo Fisher Scientific, Waltham, MA, USA); and ELN (ab23747, Abcam, Cambridge, UK). To normalize results, the $\beta$-actin antibody (A1978, Sigma-Aldrich, Saint Louis, MO, USA) was used as housekeeping control. Signal visualization of proteins was carried out by incubating the membranes with chemiluminescence reagents (ECL Plus, Amersham GE Healthcare, Buckinghamshire, UK). Densitometry of films was performed using Image J 1.42q software. Results of target protein expression are expressed as the percentage of the densitometry of the endogenous controls $\beta$-actin.

\subsection{Statistical Analyses}

Results from cellular in vitro experiments were expressed as the mean \pm standard error (SE) of $n$ experiments; $p<0.05$ was considered statistically significant. Normal distribution for each data set was confirmed by the Kolmogorov-Smirnov test. Statistical analysis was carried out by multiple comparisons with analysis of variance (ANOVA) followed by Bonferroni post hoc test. Results from the human in vivo experiments were expressed as the mean \pm standard error (SE) of $n$ experiments; $p<0.05$ was considered statistically significant. When the comparisons concerned only 2 groups (healthy vs. PTX T1), statistical analysis was carried out by unpaired $t$-test. Multiple comparisons were analyzed by ANOVA followed by the Bonferroni post hoc test. 


\section{Results}

\subsection{Paclitaxel Affects the Hydration Levels in the Skin}

The stratification of the 3D epidermis cell model was confirmed by the hematoxylineosin staining. As shown in Figure 1A, keratinocytes were distributed into the principal epidermis layers: basal, spinous, and granular, and its terminal differentiation resulted in the presence of the stratum corneum, analogously to the epidermal in vivo structure of healthy skin.

3D EPIDERMIS CELL MODEL

A.

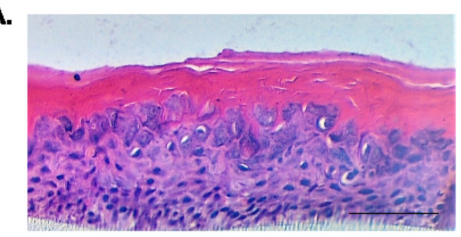

B.

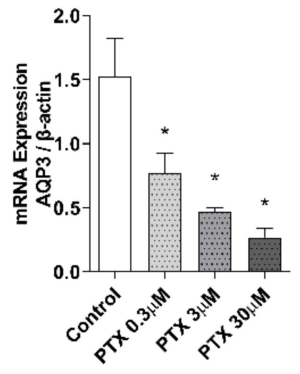

C.
D.
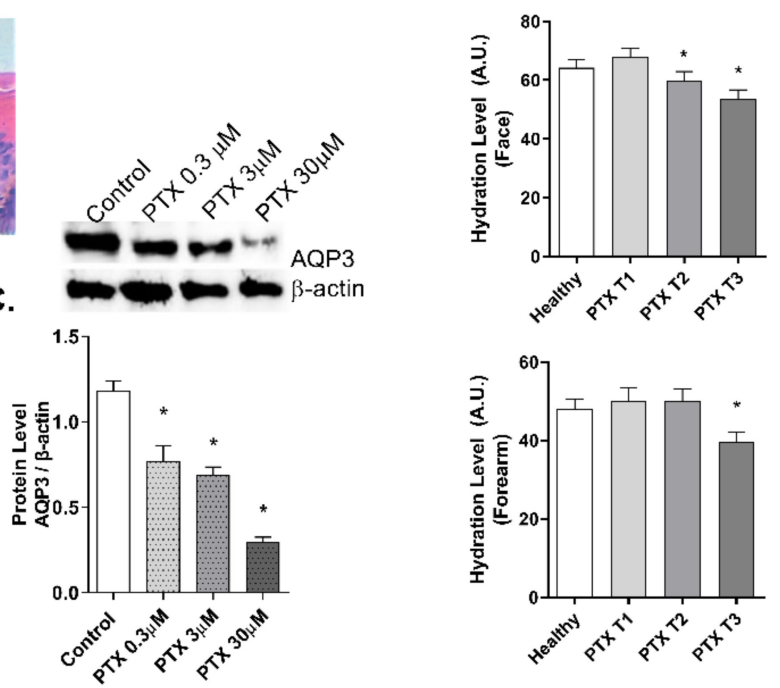

PATIENTS
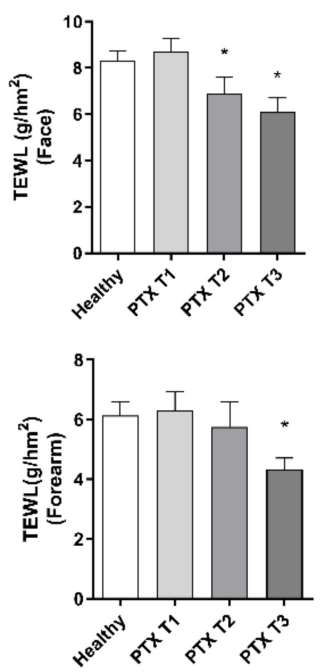

Figure 1. Paclitaxel induces a dose-dependent loss of hydration levels in oncologic patients and reduces the expression of the hydration marker AQP3 in the 3D epidermal cell model. (A) Paraffin section from the 3D epidermis model stained with hematoxylin and eosin. Scale bar $100 \mu \mathrm{m}$. (B) Three-dimensional epidermal cell model tissues were incubated for $24 \mathrm{~h}$ with increasing paclitaxel (PTX) concentrations. Aquaporin (AQP3) mRNA levels were measured by real-time PCR. Data are expressed as $2^{-\Delta C t}$. (C) Three-dimensional epidermal cell model tissues were incubated for $24 \mathrm{~h}$ with increasing paclitaxel (PTX) concentrations. AQP3 protein levels were analyzed by Western blotting. Quantification was performed by densitometry and normalized to $\beta$-actin. Results are expressed as the mean \pm standard deviation of two independent experiments $(n=3) ;{ }^{*} p<0.05 \mathrm{vs}$. control. Uncropped Western Blots can be found at Supplementary File. (D) Hydration levels were measured in 20 oncologic patients before (T1), during (T2), and after (T3) treatment with PTX, and in 20 healthy subjects as a control group. Measurements were conducted with Corneometer CM $825^{\circledR}$ in the cheekbone and forearm. Transepidermal water loss (TEWL) levels were measured in 20 oncologic patients before (T1), during (T2), and after treatment (T3) with PTX, and in 20 healthy subjects as a control group. Measurements were conducted with Tewameter TM $300^{\circledR}$ in the cheekbone and forearm. Results are expressed as the mean \pm standard deviation of at least 3 measurements each time $(n=20) ;{ }^{*} p<0.05$ vs. T1.

The effects of PTX treatment in the hydration molecular marker aquaporin (AQP3) in the 3D skin model were examined. Incubation with PTX for $24 \mathrm{~h}$ induced a dosedependent decrease in gene expression that was statistically significant (Figure 1B). Further, incubation of the 3D skin model with PTX for $24 \mathrm{~h}$ induced a similar significant decrease in AQP3 protein expression in all doses (Figure 1C). Hydration was also measured with Corneometer ${ }^{\circledR}$ on the cheekbone and forearm of the oncologic patients and to the control group (Figure 1D). No statistically significant differences were observed between the values of the control subjects and the values of cancer patients before treatment (T1). However, after three (T2) and six (T3) PTX cycles, both areas of skin manifested reduced hydration values. At the T3 timepoint, the variation percentages were $-18.73 \% \pm 5.42$ and 
$-16.38 \% \pm 5.67$ in the cheekbone and forearm, respectively. TEWL was also examined in the cheekbone and forearm with Tewameter ${ }^{\circledR}$ (Figure 1D). No statistically significant differences were observed in TEWL between the control group and the cancer patients before treatment (T1). Chemotherapeutic treatment with PTX decreased the TEWL value in the second (T2) and third (T3) visits. The differences were statistically significant in the forearm area at the T3 timepoint, and in the cheek area at T2 and T3 timepoints (Figure 1B). Medium TEWL percentage variations at T3 were $-26.67 \% \pm 8.63$ in the cheekbone and $-18.56 \% \pm 9.49$ in the forearm.

\subsection{Paclitaxel Induces a Decrease in Elasticity and Firmness of the Skin}

Incubation of the 3D skin model with PTX for $24 \mathrm{~h}$ induced a decrease in the gene expression of the three analyzed skin elasticity and firmness markers: COL1, ELN, and FN1. The mRNA downregulation was dose-dependent (Figure 2A). In the same way, treatment with PTX for $24 \mathrm{~h}$ induced the same response at the protein level, decreasing COL1, ELN, and FN1 protein expression in all doses (Figure 2B).

\section{A: 3D EPIDERMIS CELL MODEL}
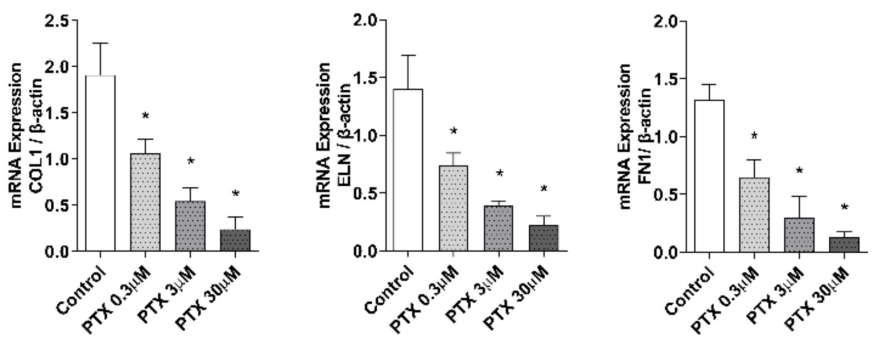

\section{B: 3D EPIDERMIS CELL MODEL}
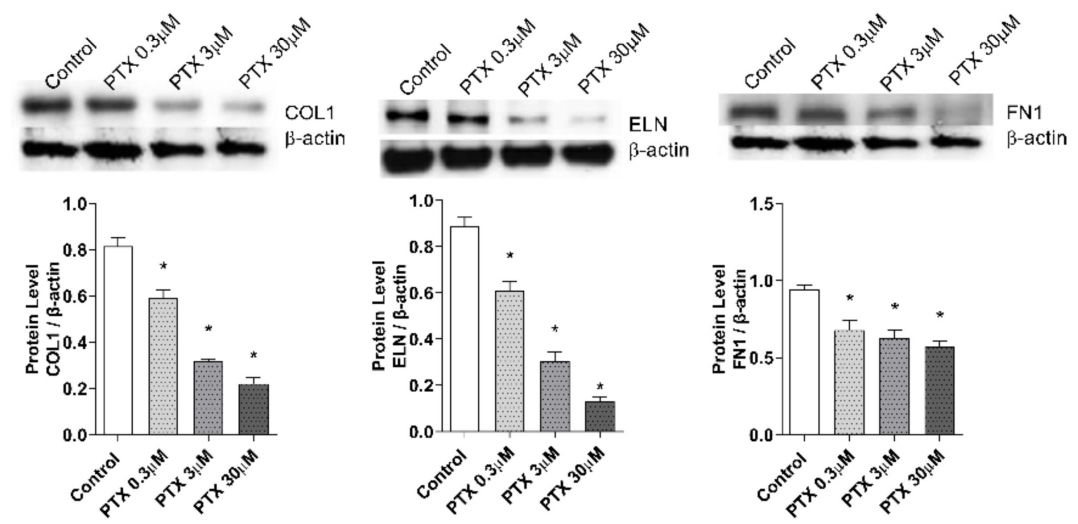

\section{C: PATIENTS}

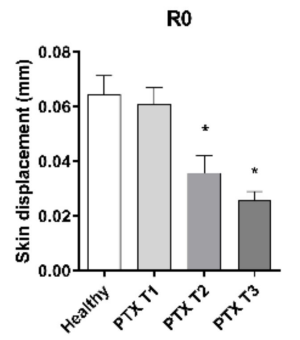

R5

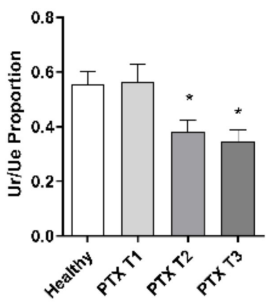

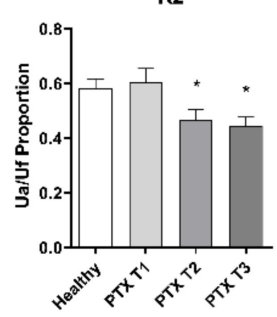

R7

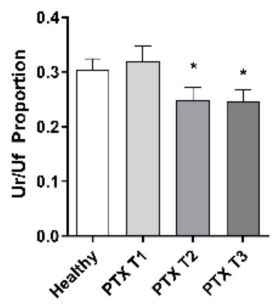

Figure 2. Paclitaxel impairs skin elasticity and firmness in oncologic patients and reduces the expression of elasticity and firmness molecular markers in a 3D epidermis model. (A) The 3D epidermis models were incubated for $24 \mathrm{~h}$ with increasing paclitaxel (PTX) concentrations. Collagen type 1 (COL1), elastin (ELN), and fibronectin (FN1) mRNA levels were measured by real-time PCR. Data are expressed as $2^{-\Delta C t}$. (B) The 3D epidermis models were incubated for $24 \mathrm{~h}$ with increasing PTX concentrations. COL1, ELN, and FN1 protein levels were analyzed by Western blotting. Quantification was performed by densitometry and normalized to $\beta$-actin. Results are expressed as the mean \pm standard deviation of two independent experiments $(n=3) ;{ }^{*} p<0.05$ vs. control. Uncropped Western Blots can be found at Supplementary File. (C) The elasticity and firmness parameters R9, R2, R5, and R7 were measured in 20 oncologic patients before (T1), during (T2), and after (T3) treatment with PTX, and in 20 healthy subjects as a control group. Measurements were conducted with Cutometer ${ }^{\circledR}$ MPA 580 probe in the cheekbone. Results are expressed as the mean \pm standard deviation of at least 3 measurements each time $(n=20) ;{ }^{*} p<0.05$ vs. T1. 
The effect of PTX on the elasticity and firmness of the skin was also evaluated in oncologic patients using Cutometer ${ }^{\circledR}$ (Figure 2C). In all parameters analyzed no differences were observed between the healthy volunteers and the oncologic patients before treatment (T1). However, treatment with PTX induced significant reductions in all values at T2 and T3 timepoints. The mean variations at T3 were R0: $-47.21 \% \pm 8.33, \mathrm{R} 2:-19.69 \% \pm 6.10$, R5: $-33.06 \% \pm 5.92$, and R7: $-19.40 \% \pm 7.09$.

\subsection{Paclitaxel Affects Sebum and Erythema Levels in the Skin}

The effects of PTX on skin lipids were evaluated by measuring the skin sebum production with Sebumeter ${ }^{\circledR}$ (Figure 3A), and its effects on skin redness were evaluated by measuring the erythema value obtained with Mexameter ${ }^{\circledR}$ (Figure 3B). In both parameters, no differences were encountered between the healthy group and the oncologic group previously to treatment (T1). After three PTX cycles (T2), the sebum levels were slightly reduced but not significant, while the erythema values remained constant. After six PTX cycles (T3), sebum levels were reduced significantly with a variation percentage of $-45.29 \% \pm 8.23$ and the erythema value increased with a mean variation of $13.96 \% \pm 4.11$.

A

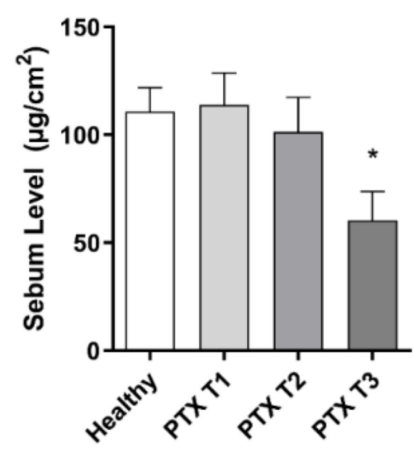

B.

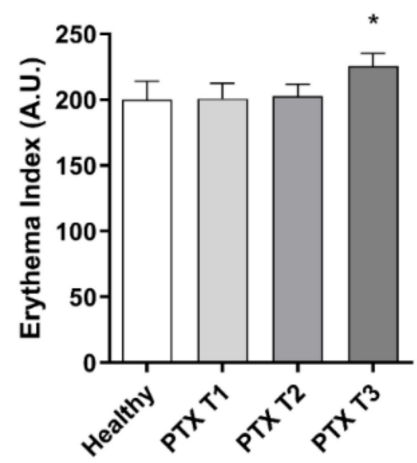

Figure 3. Paclitaxel reduces sebum levels and increases erythema in oncologic patients. (A) Sebum levels were measured in 20 oncologic patients before (T1), during (T2), and after (T3) treatment with PTX, and in 20 healthy subjects as a control group. Sebumeter SM $815^{\circledR}$ was used to obtain the forehead sebum value. (B) The erythema index was measured in 20 oncologic patients before (T1), during (T2), and after treatment (T3) with PTX, and in 20 healthy subjects as a control group. Mexameter MX $18^{\circledR}$ was used to determine the forearm erythema. Results are expressed as the mean \pm standard deviation of at least 3 measurements each time $(n=20) ;{ }^{*} p<0.05$ vs. T1.

\subsection{Paclitaxel Impairs Smoothness and Increases Roughness of Skin in Oncologic Patients}

The smoothness (Sesm) and roughness (Ser) parameters were also evaluated on the skin of oncologic patients with the Visioscan ${ }^{\circledR}$ equipment. As seen on the representative images in Figure 4C, treatment with PTX worsened the aspect of the skin surface at T2 and T3 timepoints. The Visiosca ${ }^{\circledR}$ software analyzed each image and displayed the Ser (Figure 4A) and Sesm (Figure 4B) parameters. Ser is directly proportional to roughness and Sesm is inversely proportional to smoothness. No differences were observed between the Ser and Sesm values of healthy volunteers and oncological patients before treatment (T1). However, chemotherapeutic treatment with PTX produced an increase in Ser and Sesm values, after six cycles of PTX (T3) (Figure 4A,B), which represent a loss in skin smoothness and an increased roughness. The mean Ser variation at T3 was $49.02 \% \pm 17.94$ and the mean Sesm variation was $20.54 \% \pm 5.80$. 
A.

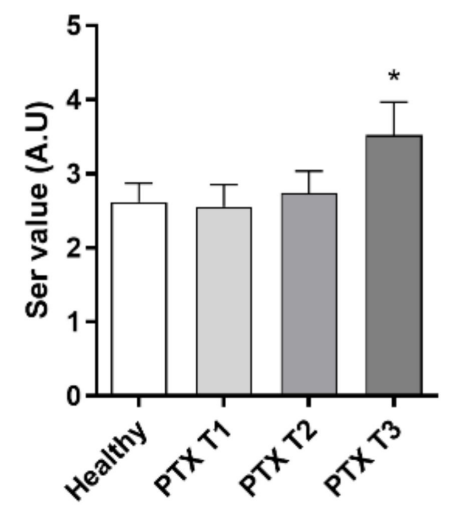

B.

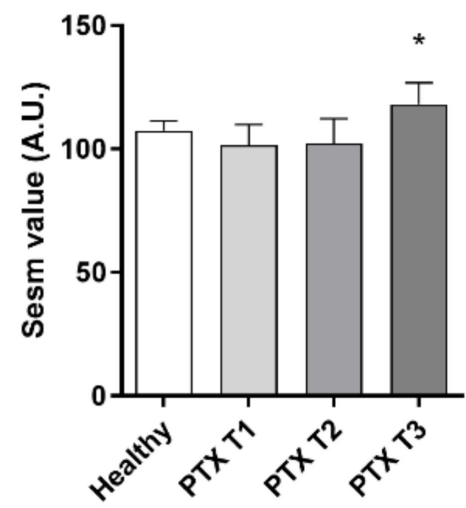

C.

$\mathrm{T} 1$

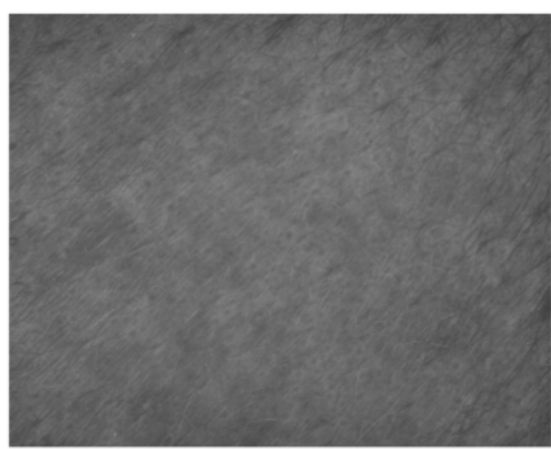

T2

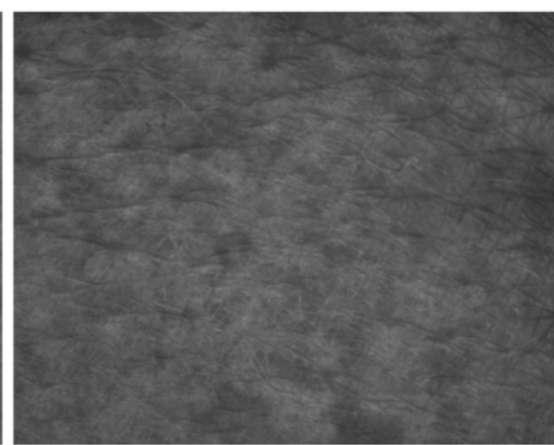

T3

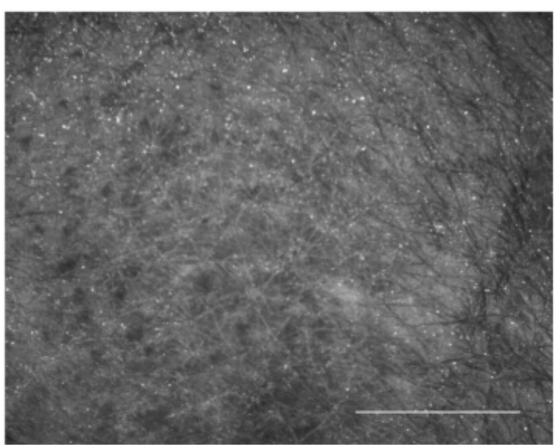

Figure 4. Paclitaxel induces an increase of skin roughness and reduces its smoothness in cancer patients. (A,B) Skin roughness and smoothness were measured in 20 oncologic patients before (T1), during (T2), and after (T3) treatment with paclitaxel (PTX), and in 20 healthy subjects as a control group. Measurements were conducted in the cheekbone by Visioscan ${ }^{\circledR}$ VC 98 probe, obtaining the Ser and Sesm values calculated by the software from each grayscale photograph. Results are expressed as the mean \pm standard deviation of at least 3 measurements each time $(n=20) ;{ }^{*} p<0.05$ vs. T1. (C) Representative images of the skin topography obtained with Visioscan ${ }^{\circledR}$ during PTX treatment at time points T1, T2, and T3. White and bright gray on the images are associated with a bad condition of the skin. Scale bar $1 \mathrm{~mm}$.

\subsection{Paclitaxel Increases the Skin Desquamation Levels in Oncologic Patients}

The effect of PTX on skin desquamation was evaluated by combining the Corneofix ${ }^{\circledR}$ tape sheets with the Visioscan ${ }^{\circledR}$ equipment. Visioscan ${ }^{\circledR}$ software displays a color-graded image of the Corneofix ${ }^{\circledR}$ tape with the attached corneocytes. As shown in the representative images in Figure 5A, higher blue staining at T2 and T3 represent higher desquamation levels. The analyzed desquamation percentage is shown in Figure 5B. While no differences were observed between the percentage of desquamation of healthy volunteers and cancer patients at T1, treatment with PTX increased skin peeling, with statistically significant differences after six PTX cycles (T3). The mean variation at T3 compared to T1 was $14.94 \% \pm 3.17$. 
A. T1

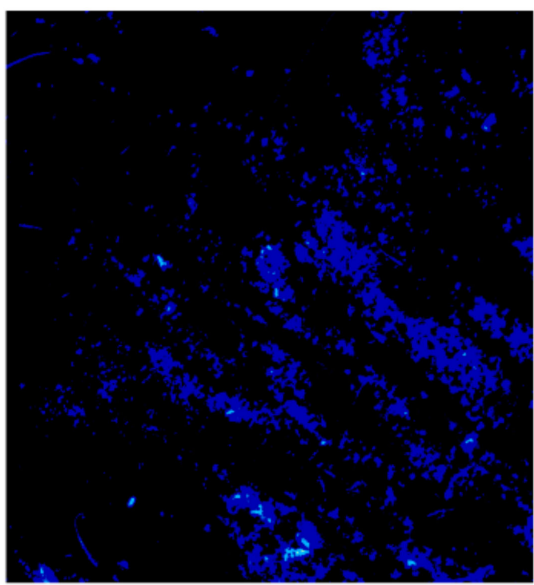

T2

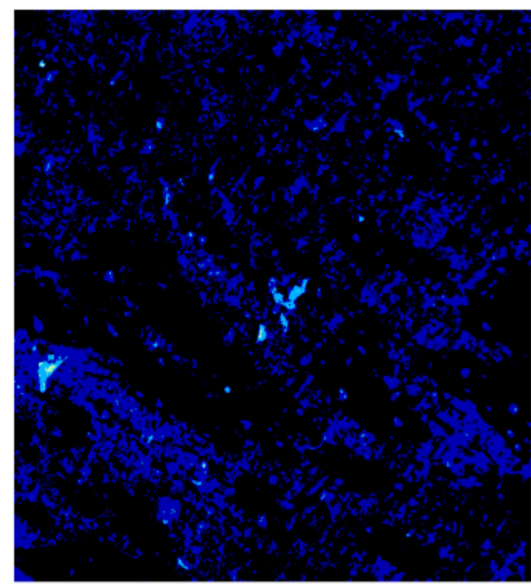

T3

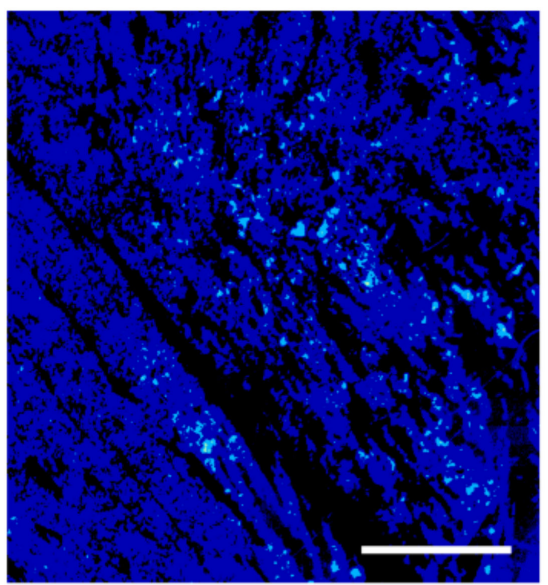

B.

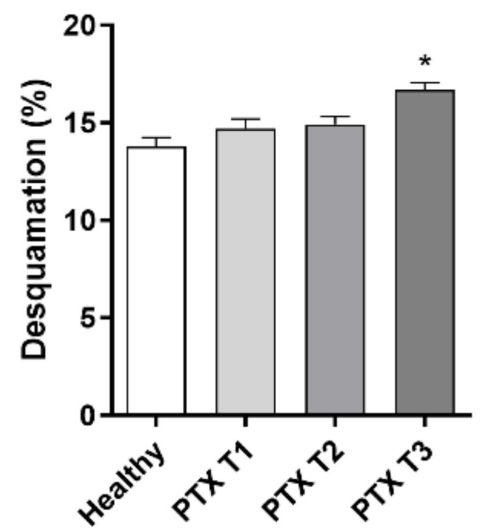

Figure 5. Paclitaxel increases the skin desquamation levels in oncologic patients. (A) Representative Corneofix ${ }^{\circledR}$ tape images obtained before (T1), during (T2), and after (T3) treatment with paclitaxel. Images were obtained with the Visioscan ${ }^{\circledR}$ probe. The blue color on the image represents higher desquamation levels. Scale bar $1 \mathrm{~mm}$. (B) Skin desquamation percentage was measured in 20 oncologic patients after PTX treatment at T1, T2, and T3 timepoints and in 20 healthy subjects as a control group. Measurements were conducted on the forehead with the combination of the Corneofix ${ }^{\circledR}$ tape and the Visioscan ${ }^{\circledR}$ probe. Results are expressed as the mean \pm standard deviation of at least 3 measurements each time $(n=20) ;{ }^{*} p<0.05$ vs. T1.

\subsection{Paclitaxel Reduces Skin Thickness in Oncologic Patients}

The ultrasound technique of Ultrascan ${ }^{\circledR}$ UC22 was used to analyze the thickness of the different layers of the skin in oncologic patients. Epidermis, dermis, and the total thickness of the skin were similar in the healthy group and patients before treatment. After three and six PTX cycles, all layers of skin showed a decrease in thickness, which can be noted in the representative images in Figure 6A. The mean thickness variations in comparison to T1 were $-34.37 \% \pm 3.50$ in epidermis, $-12.75 \% \pm 2.05$ in the dermis, and $-16.46 \% \pm 1.58$ for total skin thickness (Figure 6B). 
A. T1

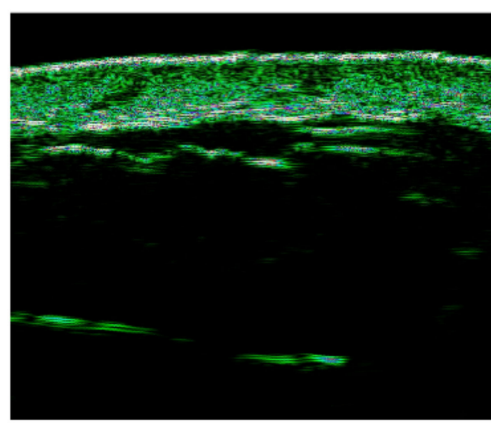

B.

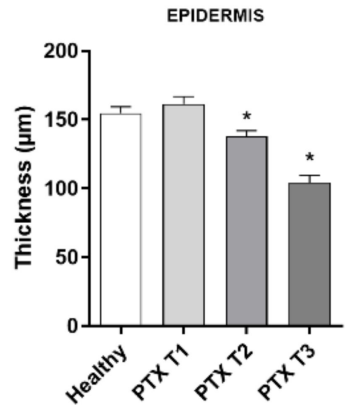

T2

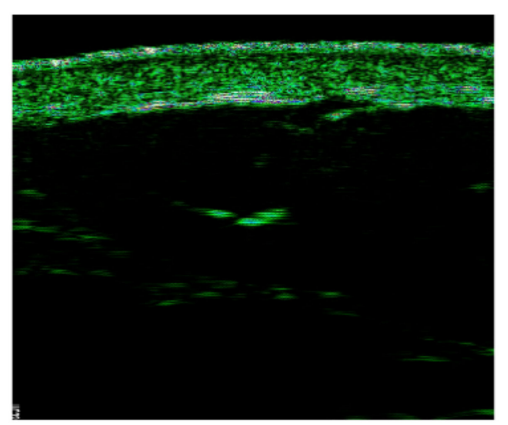

DERMIS

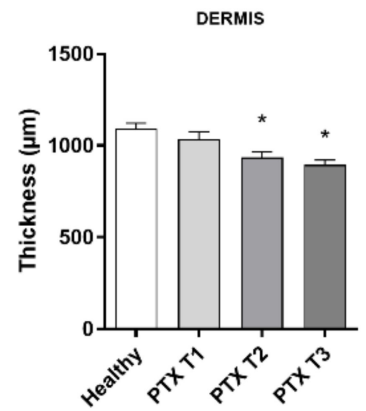

T3

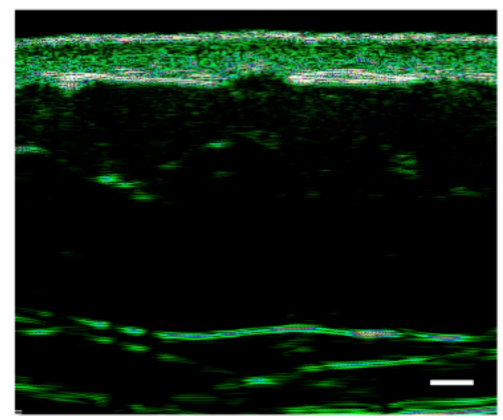

TOTAL

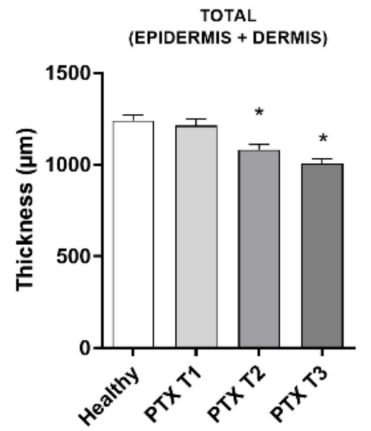

Figure 6. Paclitaxel reduces skin thickness in oncologic patients. (A) Representative ultrasound images of the skin thickness obtained during treatment with PTX in 20 oncologic patients before (T1), during (T2), and after (T3) treatment. Images were obtained with Ultrascan ${ }^{\circledR}$ UC22. Scale bar 1 mm. (B) Epidermis, dermis, and total skin thickness measured in 20 oncologic patients under PTX treatment at timepoints T1, T2, and T3, and in 20 healthy subjects as a control group. Measurements were conducted on the forearm with Ultrascan ${ }^{\circledR} \mathrm{UC} 22$. Results are expressed as the mean \pm standard deviation of at least 3 measurements each time $(n=20){ }^{*} p<0.05$ vs. T1.

\section{Discussion}

Paclitaxel is an antineoplastic drug widely used in cancer treatment that has been shown to produce a multitude of skin adverse effects [39]. However, the subclinical alterations caused by PTX on the skin have not previously been described. In this study, we investigated these events in oncologic patients under PTX treatment by measuring hydration, TEWL, sebum, elasticity, erythema, roughness, desquamation, and thickness of the skin. The study was carried out without the development of skin reactions. The use of the Courage-Khazaka Electronic probes allowed us to measure the different skin parameters without the need of performing histological analysis of skin biopsies. To support these findings with in vitro experiments, we used a 3D epidermis model of keratinocytes grown on a feeder layer and exposed to the air-liquid interface. Hematoxylin-eosin staining demonstrated the development of a fully differentiated epidermis. The 3D epidermis model was used as a mimicker of a healthy epidermis to evaluate molecular modulation induced after treatment with the clinically achievable plasma concentrations of PTX.

In this study, oncologic patients did not report visible cutaneous symptoms. The values of the skin properties in oncologic patients before treatment (T1) were compared to the values of a healthy control group. In all cases, the parameters were similar and no statistically significant differences were encountered between both groups. This shows that before treatment with PTX, all patients had skin parameters within the normal biological values, representative of the general population. Additionally, data obtained from healthy volunteers and cancer patients in their first visit were within the reference values, as described by the literature $[29,30,40,41]$.

Firstly, we analyzed the hydration levels and TEWL. In the epidermis cell model, treatment with PTX reduced the gene and protein expression of the marker Aquaporin 
(AQP3). AQP3 is the most abundant skin aquaglyceroporin and is responsible for transporting water and glycerol in the epidermis. Therefore, AQP3 is a key protein in the maintenance of epidermal hydration and differentiation of keratinocytes [42-44]. Only one case report has related PTX and aquaporins previously: A patient under PTX treatment developed a cystoid macular edema induced by the functional failure of aquaporin mediated water transport [45]. This finding, in line with our results, suggests that PTX induces the modulation of aquaporins. In addition, aquaporins are reported to play a major role in angiogenesis, cell proliferation, apoptosis, and cell migration [46]. Thereby, PTX could be impairing other cellular processes through the modulation of AQP3. To see if these molecular changes could directly affect the skin in patients under PTX treatment, we measured hydration levels and transepidermal water loss (TEWL). In agreement with the in vitro results, patients showed reduced face hydration levels after three and six PTX cycles. Hydration values on the forearm were significantly reduced after six PTX cycles. This difference can be explained by the fact that the face is a photoexposed area, and the damage produced by sunlight on skin cells might enhance the dehydration induced by PTX $[47,48]$. Skin dehydration in oncologic patients can lead to the reduction of the skin water content. Indeed, patients showed a decrease in TEWL in comparison to the values obtained before treatment. TEWL is an indicator of the ability of the epidermis to hold water and is a good marker of the functionality of the skin barrier [30]. In patients with taxane-related xerosis, TEWL appears increased [14]. We suggest that these differences might be explained by the fact that patients with xerosis have a developed skin adverse effect, while patients in this study did not show any symptomatic alterations. The effects of PTX in this study represent the early modifications that could lead to the development of later adverse effects. Furthermore, because lipids act as a barrier against water loss [49], we also analyzed the sebum levels in oncologic patients. Sebum levels showed a progressive decrease with the progression of PTX treatment, which represents the loss of its skin protection layer. Overall, we can state that PTX proved to impair skin moisturization in oncologic patients and compromised the skin barrier function.

The epidermis cell model was also incubated with PTX to analyze collagen 1 (COL1), elastin (ELN), and fibronectin (FN1) expression. These proteins play a key role in maintaining the elasticity, firmness, and support of the skin layers [50-52]. Gene and protein expression of these markers was significantly reduced after PTX treatment on the 3D epidermis model. In agreement with these results, a study on tenon fibroblasts monolayers showed that both collagen and fibronectin were markedly downregulated in the culture medium $[53,54]$. There is also in vivo evidence that showed alterations in collagen in a skin biopsy from a sclerodermatous area of a patient under taxane treatment [55]. These results are directly related to those obtained in our in vivo study on cancer patients treated with PTX. Oncologic patients had decreased skin elasticity and firmness as shown by the lowered $\mathrm{R}$ parameters, which represent the state of the biomechanical elastic properties of the skin [56-58]. These results suggest that PTX-induced decrease in the skin elasticity and firmness might be mediated by its capacity to modulate molecular markers such as COL1, ELN, and FN1, which maintain the structure of the skin layers.

Erythema is a common adverse effect seen on patients under PTX treatment [13,59]. In this study, patients did not develop clinically visible erythema. However, we wanted to analyze the possible subclinical manifestations. Colorimetric examinations with Mexameter ${ }^{\circledR}$ showed that the erythema index had a slight increase after six PTX cycles. It is widely described that treatment with taxanes induces erythema at different areas of skin and in different grades of severity $[14,60,61]$. However, this is the first study that reported erythemal changes on the skin under PTX treatment before the development of clinically visible erythematous skin reactions.

As it was evident that PTX induced changes in the biomechanical properties of skin, roughness and softness were also examined. PTX induced an increase in skin roughness and a decrease in smoothness. Connected to these events, patients showed an increased desquamation percentage. This implies a decrease in the barrier function capacity of the skin 
after PTX treatment. Similar to the other parameters analyzed, the research data available comes from case reports of patients suffering from PTX-induced toxicities with clinical manifestations. In this case, desquamation had been previously described in patients under PTX treatment, in the palms and soles, necessitating treatment interruption [62] and associated with rash reactions [63]. Regarding the thickness of the skin, PTX induced the reduction of the dermis, epidermis, and total skin thickness. These results were expected, bearing in mind that PTX induced the reduction of the structural proteins COL1, FN1, and ELN, which causes an impairment of the skin's architecture, and therefore changes in its thickness. This effect of PTX has not been described previously. However, there is a case report describing acanthotic epidermis in a PTX-induced cutaneous eruption [16], which indicates the potential of PTX to induce changes in the structure of the skin.

There are a few study limitations to be mentioned. Firstly, the heterogeneity of the sample-there are patients with localized disease and patients in different situations of advanced disease. Therefore, the chemotherapy administration schemes differ between patients. However, the heterogeneity of the sample should not have a significant impact since it includes only gynecological tumors with similar treatments. Secondly, considering the treatments used, the drug with the greatest impact at the cutaneous level was PTX. We acknowledge that carboplatin causes skin adverse effects but they are usually associated with hypersensitivity reactions [64]. As the number of patients was limited, and the purpose of the study was to analyze asymptomatic skin alterations, it was considered that the other drugs used in combination with PTX will not significantly bias our data. Finally, as not all patients were exposed to taxanes for the first time, a healthy population was included as a control group to prove that the baseline results of cancer patients before treatment were not statistically different from the healthy volunteers. This comparison served to prove that, in the patients included in the study, accumulated doses of paclitaxel did not affect the severity of the alterations.

The results of this study show that, although PTX did not cause severe skin adverse reactions, it impaired its physical, physiological, and biomechanical properties with no clinical manifestations. Treatment with PTX induced skin dehydration, a decrease in elasticity, thickness, and sebum levels, and an increase in skin desquamation and erythema. These changes were related to the modulation of gene and protein expression induced by PTX in an epidermis cell model that mimics a healthy epidermis. These results indicate that PTX can alter the skin structure, and impair its barrier function, inducing cutaneous changes that do not become symptomatic. Previous studies have described PTX-induced epithelial damage in zebrafish models $[19,20]$ and some case reports show histologic changes caused by PTX on the skin $[16,17]$. However, to our knowledge, this is the first study that analyzes the subclinical alterations caused by PTX and it might explain the prediction of later severe cutaneous adverse events. Skin symptoms in patients cause physical pain and discomfort and psychological distress. In severe cases, skin toxicities can cause treatment delays and even discontinuation, which affects clinical outcomes [65]. This highlights the need for the early management of these alterations. There is a relative lack of evidence for effective management of taxane skin toxicities [66]. Some studies recommend using a scalp cooling system to reduce alopecia, frozen gloves to prevent nail and cutaneous hand changes [12], and nail solution to prevent chemotherapy-induced nail toxicity [67]. Additionally, a preliminary study in patients undergoing chemotherapy with taxanes demonstrated that resveratrol, lycopene, vitamin C, and anthocyanins (Ixor ${ }^{\circledR}$ ) had a protective role against skin reactions [68]. However, there is still a lack of studies that propose prophylactic measures to prevent skin alterations in patients under paclitaxel treatment.

In conclusion, the results provided by this work suggest the need for prophylactic measures that improve the patient's quality of life as well to ensure adherence to treatment. Although more studies addressing this matter are needed, early introduction of effective countermeasures including daily skincare (skin cleansing, moisturization, and irritation prevention) would help in the prevention of future PTX-induced skin toxicities. 


\section{Conclusions}

This work has shown that paclitaxel impairs different physical, physiological, and biomechanical properties of the skin. To our knowledge, this is the first study that has concluded that gynecological cancer patients under paclitaxel treatment show subclinical skin alterations. These subclinical alterations include the decrease of hydration, TEWL, sebum, elasticity, and thickness of the skin, together with an increase in erythema, roughness, and desquamation. Further, this study showed the PTX-induced modulation of molecular markers related to hydration and the support of the skin layers in a 3D epidermis model. These altogether highlight the lack of management measures to prevent skin alterations in patients under taxane treatment. The use of prophylactic measures at the early stages of treatment could be useful to avoid these subclinical alterations and prevent future severe reactions.

Supplementary Materials: The following supporting information can be downloaded at: https: / / www.mdpi.com/article/10.3390/cancers14051146/s1, Supplementary file: un-cropped images of the original western blots from which figures have been derived.

Author Contributions: Conceptualization, J.A.P.-F., C.S., A.C., and J.C.; methodology P.M., M.P.-L., C.E., and I.R.; validation, J.A.P.-F., C.S., J.M., A.C., and J.C.; formal analysis, P.M., M.P.-L., C.E., and I.R.; investigation, P.M., M.P.-L., C.E., and I.R.; resources, J.C.; writing-original draft preparation, P.M.; writing-review and editing, P.M., M.P.-L., and J.C.; supervision, J.C.; project administration, J.C.; funding acquisition, J.C. All authors have read and agreed to the published version of the manuscript.

Funding: This work was supported by the grants PID2020-114871RB-I00 (JC), European Regional Development Fund (FEDER), and Instituto de Salud Carlos III, PI20/01363 (JM), CIBERES (CB06/06/0027) from the Spanish Government, and by research grants from the Regional Government Prometeo 2017/023/UV (JC), from “Generalitat Valenciana". Funding entities did not contribute to the study design or data collection, analysis, and interpretation, or to the writing of the manuscript.

Institutional Review Board Statement: The study was conducted according to the guidelines of the Declaration of Helsinki, and approved by the research Ethics Committee from the Clinical Hospital from Valencia (approval date 29 November 2018) and by the Council of Public Health from Generalitat Valenciana (date of approval 2 February 2019), ethical approval code: INC-PAC-2018-01.

Informed Consent Statement: Informed consent was obtained from all subjects involved in the study. Written informed consent has been obtained from the patient(s) to publish this paper.

Data Availability Statement: The data presented in this study are available on request from the corresponding author.

Conflicts of Interest: The authors declare no conflict of interest.

\section{References}

1. Kuroda, S.; Kagawa, S.; Fujiwara, T. Chapter 12-Selectively replicating oncolytic adenoviruses combined with chemotherapy, radiotherapy, or molecular targeted therapy for treatment of human cancers. In Gene Therapy of Cancer, 3rd ed.; Lattime, E.C., Gerson, S.L., Eds.; Academic Press: San Diego, CA, USA, 2014; pp. 171-183.

2. Alqahtani, F.Y.; Aleanizy, F.S.; El Tahir, E.; Alkahtani, H.M.; AlQuadeib, B.T. Chapter Three-Paclitaxel. In Profiles of Drug Substances, Excipients and Related Methodology; Brittain, H.G., Ed.; Academic Press: San Diego, CA, USA, 2019; pp. $205-238$.

3. Mekhail, T.M.; Markman, M. Paclitaxel in cancer therapy. Expert Opin. Pharmacother. 2002, 3, 755-766.

4. Wang, T.H.; Wang, H.S.; Soong, Y.K. Paclitaxel-induced cell death: Where the cell cycle and apoptosis come together. Cancer 2000, 88, 2619-2628. [CrossRef]

5. McGuire, W.P.; Hoskins, W.J.; Brady, M.F.; Kucera, P.R.; Partridge, E.E.; Look, K.Y.; Clarke-Pearson, D.L.; Davidson, M. Cyclophosphamide and cisplatin compared with paclitaxel and cisplatin in patients with stage III and stage IV ovarian cancer. N. Engl. J. Med. 1996, 334, 1-6. [CrossRef] [PubMed]

6. $\quad$ Piccart, M.J.; Bertelsen, K.; James, K.; Cassidy, J.; Mangioni, C.; Simonsen, E.; Stuart, G.; Kaye, S.; Vergote, I.; Blom, R.; et al. Randomized intergroup trial of cisplatin-paclitaxel versus cisplatin-cyclophosphamide in women with advanced epithelial ovarian cancer: Three-year results. J. Natl. Cancer Inst. 2000, 92, 699-708. [CrossRef] [PubMed] 
7. Markman, M.; Blessing, J.; Rubin, S.C.; Connor, J.; Hanjani, P.; Waggoner, S. Phase II trial of weekly paclitaxel $\left(80 \mathrm{mg} / \mathrm{m}^{2}\right)$ in platinum and paclitaxel-resistant ovarian and primary peritoneal cancers: A Gynecologic Oncology Group study. Gynecol. Oncol. 2006, 101, 436-440. [CrossRef] [PubMed]

8. Zhu, L.; Chen, L. Progress in research on paclitaxel and tumor immunotherapy. Cell. Mol. Biol. Lett. 2019, 24, 40. [CrossRef]

9. Guastalla, J.P., III; Diéras, V. The taxanes: Toxicity and quality of life considerations in advanced ovarian cancer. Br. J. Cancer 2003, 89, S16-S22. [CrossRef]

10. Michaud, L.B.; Valero, V.; Hortobagyi, G. Risks and benefits of taxanes in breast and ovarian cancer. Drug Saf. 2000, 23, 401-428. [CrossRef]

11. Staff, N.P.; Fehrenbacher, J.C.; Caillaud, M.; Damaj, M.I.; Segal, R.A.; Rieger, S. Pathogenesis of paclitaxel-induced peripheral neuropathy: A current review of in vitro and in vivo findings using rodent and human model systems. Exp. Neurol. 2020, 324, 113121. [CrossRef]

12. Marks, D.H.; Qureshi, A.; Friedman, A. Evaluation of Prevention Interventions for Taxane-Induced Dermatologic Adverse Events: A Systematic Review. JAMA Dermatol. 2018, 154, 1465-1472. [CrossRef]

13. Cohen, P.R. Photodistributed erythema multiforme: Paclitaxel-related, photosensitive conditions in patients with cancer. J. Drugs Dermatol. 2009, 8, 61-64. [PubMed]

14. Sibaud, V.; Lebœuf, N.R.; Roche, H.; Belum, V.R.; Gladieff, L.; Deslandres, M.; Montastruc, M.; Eche, A.; Vigarios, E.; Dalenc, F.; et al. Dermatological adverse events with taxane chemotherapy. Eur. J. Dermatol. 2016, 26, 427-443. [CrossRef]

15. Eich, D.; Scharffetter-Kochanek, K.; Eich, H.T.; Tantcheva-Poor, I.; Krieg, T. Acral erythrodysesthesia syndrome caused by intravenous infusion of docetaxel in breast cancer. Am. J. Clin. Oncol. 2002, 25, 599-602. [CrossRef] [PubMed]

16. Salas-Martínez, A.-M.; Caballero, C.I.; González-Vela, M.C.; Mira, M.-C.; Laso-Dosal, F.; Val-Bernal, J.-F. Paclitaxel-induced cutaneous change mimicking malignancy in a previous cutaneous eruption. Rev. Esp. Patol. 2018, 51, 188-192. [CrossRef] [PubMed]

17. Prieto-Torres, L.; Llamas-Velasco, M.; Machan, S.; Haro, R.; de Asis, S.; Carmo, M.; Loredo, A.; del Puerto, C.; Fried, I.; Kempf, W.; et al. Taxanes-induced cutaneous eruption: Another histopathologic mimicker of malignancy. J. Eur. Acad. Dermatol. Venereol. 2016, 30, 638-644. [CrossRef] [PubMed]

18. Hokeness, K.; Qiu, L.H.; Vezeridis, M.; Yan, B.F.; Mehta, S.; Wan, Y.S. IFN-gamma enhances paclitaxel-induced apoptosis that is modulated by activation of caspases 8 and 3 with a concomitant down regulation of the AKT survival pathway in cultured human keratinocytes. Oncol. Rep. 2005, 13, 965-969.

19. Lisse, T.S.; Middleton, L.J.; Pellegrini, A.D.; Martin, P.B.; Spaulding, E.L.; Lopes, O.; Brochu, E.A.; Carter, E.V.; Waldron, A.; Rieger, S. Paclitaxel-induced epithelial damage and ectopic MMP-13 expression promotes neurotoxicity in zebrafish. Proc. Natl. Acad. Sci. USA 2016, 113, E2189-E2198. [CrossRef]

20. Cirrincione, A.M.; Pellegrini, A.D.; Dominy, J.R.; Benjamin, M.E.; Utkina-Sosunova, I.; Lotti, F.; Jergova, S.; Sagen, J.; Rieger, S Paclitaxel-induced peripheral neuropathy is caused by epidermal ROS and mitochondrial damage through conserved MMP-13 activation. Sci. Rep. 2020, 10, 3970. [CrossRef]

21. Perez-Fidalgo, J.A.; Estornut Navarro, C.; Sanz Garcia, C.; Perez-Leal, M.; Poveda Ferriols, J.; Cervantes, A.; Milara Paya, J.; Cortijo Gimeno, J. Mechanisms of skin toxicity of paclitaxel: An in vitro preclinical assessment. J. Clin. Oncol. 2020, 38 , e15511. [CrossRef]

22. Stark, H.J.; Baur, M.; Breitkreutz, D.; Mirancea, N.; Fusenig, N.E. Organotypic keratinocyte cocultures in defined medium with regular epidermal morphogenesis and differentiation. J. Investig. Dermatol. 1999, 112, 681-691. [CrossRef]

23. Do Nascimento Pedrosa, T.; Catarino, C.M.; Pennacchi, P.C.; de Assis, S.R.; Gimenes, F.; Consolaro, M.E.L.; de Moraes Barros, S.B.; Maria-Engler, S.S. A new reconstructed human epidermis for in vitro skin irritation testing. Toxicol. In Vitro 2017, $42,31-37$. [CrossRef]

24. Arnette, C.; Koetsier, J.L.; Hoover, P.; Getsios, S.; Green, K.J. In Vitro Model of the Epidermis: Connecting Protein Function to 3D Structure. Methods Enzymol. 2016, 569, 287-308.

25. Pruniéras, M.; Régnier, M.; Woodley, D. Methods for Cultivation of Keratinocytes with an Air-Liquid Interface. J. Investig. Dermatol. 1983, 81, S28-S33. [CrossRef]

26. Lamb, R.; Ambler, C.A. Keratinocytes propagated in serum-free, feeder-free culture conditions fail to form stratified epidermis in a reconstituted skin model. PLOS ONE 2013, 8, e52494.

27. Bisson, F.; Rochefort, E.; Lavoie, A.; Larouche, D.; Zaniolo, K.; Simard-Bisson, C.; Damour, O.; Auger, F.A.; Guérin, S.L.; Germain, L. Irradiated human dermal fibroblasts are as efficient as mouse fibroblasts as a feeder layer to improve human epidermal cell culture lifespan. Int. J. Mol. Sci. 2013, 14, 4684-4704. [CrossRef]

28. Plessis, J.D.; Stefaniak, A.; Eloff, F.; John, S.; Agner, T.; Chou, T.-C.; Nixon, R.; Steiner, M.; Franken, A.; Kudla, I.; et al. International guidelines for the in vivo assessment of skin properties in non-clinical settings: Part 2. transepidermal water loss and skin hydration. Skin Res. Technol. 2013, 19, 265-278. [CrossRef]

29. Nedelec, B.; Forget, N.J.; Hurtubise, T.; Cimino, S.; de Muszka, F.; Legault, A.; Liu, W.L.; de Oliveira, A.; Calva, V.; Correa, J.A Skin characteristics: Normative data for elasticity, erythema, melanin, and thickness at 16 different anatomical locations. Skin Res. Technol. 2016, 22, 263-275. [CrossRef]

30. Luebberding, S.; Krueger, N.; Kerscher, M. Skin physiology in men and women: In vivo evaluation of 300 people including TEWL, SC hydration, sebum content and skin surface pH. Int. J. Cosmet. Sci. 2013, 35, 477-483. [CrossRef] 
31. Rogiers, V. EEMCO Guidance for the Assessment of Transepidermal Water Loss in Cosmetic Sciences. Skin Pharmacol. Physiol. 2001, 14, 117-128. [CrossRef] [PubMed]

32. Serup, J.; Jemec, G.B.E.; Grove, G.L. (Eds.) Handbook of Non-Invasive Methods and the Skin, 2nd ed.; CRC Press: Boca Raton, FL, USA, 2013.

33. Dabrowska, M.; Nowak, I. Noninvasive evaluation of the influence of aucubin-containing cosmetic macroemulsion on selected skin parameters. J. Cosmet. Dermatol. 2021, 20, 1022-1030. [CrossRef] [PubMed]

34. Rattanawiwatpong, P.; Wanitphakdeedecha, R.; Bumrungpert, A.; Maiprasert, M. Anti-aging and brightening effects of a topical treatment containing vitamin $\mathrm{C}$, vitamin $\mathrm{E}$, and raspberry leaf cell culture extract: A split-face, randomized controlled trial. $J$. Cosmet. Dermatol. 2020, 19, 671-676. [CrossRef]

35. Mak, V.H.; Cumpstone, M.B.; Kennedy, A.H.; Harmon, C.S.; Guy, R.H.; Potts, R.O. Barrier function of human keratinocyte cultures grown at the air-liquid interface. J. Investig. Dermatol. 1991, 96, 323-327. [CrossRef]

36. Henningsson, A.; Karlsson, M.O.; Viganò, L.; Gianni, L.; Verweij, J.; Sparreboom, A. Mechanism-based pharmacokinetic model for paclitaxel. J. Clin. Oncol. 2001, 19, 4065-4073. [CrossRef] [PubMed]

37. Gianni, L.; Kearns, C.M.; Giani, A.; Capri, G.; Viganó, L.; Lacatelli, A.; Bonadonna, G.; Egorin, M.J. Nonlinear pharmacokinetics and metabolism of paclitaxel and its pharmacokinetic/pharmacodynamic relationships in humans. J. Clin. Oncol. 1995, 13, 180-190. [CrossRef] [PubMed]

38. Gianni, L. Theoretical and practical aspects of paclitaxel scheduling. Ann. Oncol. 1995, 6, 861-863. [CrossRef] [PubMed]

39. Gligorov, J.; Lotz, J.P. Preclinical pharmacology of the taxanes: Implications of the differences. Oncologist 2004, 9, 3-8. [CrossRef] [PubMed]

40. Constantin, M.-M.; Poenaru, E.; Poenaru, C.; Constantin, T. Skin Hydration Assessment through Modern Non-Invasive Bioengineering Technologies. Maedica 2014, 9, 33-38.

41. Firooz, A.; Aghazadeh, N.; Rajabi Estarabadi, A.; Hejazi, P. The effects of water exposure on biophysical properties of normal skin. Skin Res. Technol. 2015, 21, 131-136. [CrossRef]

42. Qin, H.; Zheng, X.; Zhong, X.; Shetty, A.K.; Elias, P.M.; Bollag, W.B. Aquaporin-3 in keratinocytes and skin: Its role and interaction with phospholipase D2. Arch. Biochem. Biophys. 2011, 508, 138-143. [CrossRef]

43. Dumas, M.; Sadick, N.S.; Noblesse, E.; Juan, M.; Lachmann-Weber, N.; Boury-Jamot, M.; Sougrat, R.; Verbavatz, J.M.; Schnebert, S.; Bonté, F. Hydrating skin by stimulating biosynthesis of aquaporins. J. Drugs Dermatol. 2007, 6, s20-s24.

44. Li, C.; Wang, W. Molecular Biology of Aquaporins. Adv. Exp. Med. Biol. 2017, 969, 1-34. [PubMed]

45. Kanakis, M.; Georgalas, I.; Makatsoris, T.; Pharmakakis, N. Taxane Induced Cystoid Macular Edema: Case Report and Integrated Pathogenic Theory. Curr. Drug Saf. 2019, 14, 43-47. [CrossRef] [PubMed]

46. Abdelrahman, A.E.; Fathy, A.; Elsebai, E.A.; Nawar, N.; Etman, W.M. Prognostic impact of Apaf-1, Cyclin D1, and AQP-5 in serous ovarian carcinoma treated with the first-line chemotherapy. Ann. Diagn. Pathol. 2018, 35, 27-37. [CrossRef] [PubMed]

47. Rittié, L.; Fisher, G.J. Natural and sun-induced aging of human skin. Cold Spring Harb. Perspect. Med. 2015, 5, a015370. [CrossRef]

48. Zhang, S.; Duan, E. Fighting against Skin Aging. Cell Transplant. 2018, 27, 729-738. [CrossRef]

49. Feingold, K.R. Thematic review series: Skin lipids. The role of epidermal lipids in cutaneous permeability barrier homeostasis. $J$ Lipid Res. 2007, 48, 2531-2546. [CrossRef]

50. Clark, R.A. Fibronectin in the skin. J. Investig. Dermatol. 1983, 81, 475-479. [CrossRef]

51. Mora Huertas, A.C.; Schmelzer, C.E.H.; Hoehenwarter, W.; Heyroth, F.; Heinz, A. Molecular-level insights into aging processes of skin elastin. Biochimie 2016, 128, 163-173. [CrossRef]

52. Uitto, J. The role of elastin and collagen in cutaneous aging: Intrinsic aging versus photoexposure. J. Drugs Dermatol. 2008, 7 , s12-s16.

53. Chen, N.; Guo, D.; Guo, Y.; Sun, Y.; Bi, H.; Ma, X. Paclitaxel inhibits cell proliferation and collagen lattice contraction via TGF- $\beta$ signaling pathway in human tenon's fibroblasts in vitro. Eur. J. Pharmacol. 2016, 777, 33-40. [CrossRef]

54. Choritz, L.; Grub, J.; Wegner, M.; Pfeiffer, N.; Thieme, H. Paclitaxel inhibits growth, migration and collagen production of human Tenon's fibroblasts-Potential use in drug-eluting glaucoma drainage devices. Graefe's Arch. Clin. Exp. Ophthalmol. 2010, 248, 197-206. [CrossRef]

55. Itoh, M.; Yanaba, K.; Kobayashi, T.; Nakagawa, H. Taxane-induced scleroderma. Br. J. Dermatol. 2007, 156, 363-367. [CrossRef]

56. Ohshima, H.; Kinoshita, S.; Oyobikawa, M.; Futagawa, M.; Takiwaki, H.; Ishiko, A.; Kanto, H. Use of Cutometer area parameters in evaluating age-related changes in the skin elasticity of the cheek. Skin Res. Technol. 2013, 19, e238-e242. [CrossRef] [PubMed]

57. Ryu, H.S.; Joo, Y.H.; Kim, S.O.; Park, K.C.; Youn, S.W. Influence of age and regional differences on skin elasticity as measured by the Cutometer. Skin Res. Technol. 2008, 14, 354-358. [CrossRef]

58. Gerhardt, L.-C.; Lenz, A.; Spencer, N.D.; Münzer, T.; Derler, S. Skin-textile friction and skin elasticity in young and aged persons. Skin Res. Technol. 2009, 15, 288-298. [CrossRef]

59. Sanborn, R.E.; Sauer, D.A. Cutaneous reactions to chemotherapy: Commonly seen, less described, little understood. Dermatol. Clin. 2008, 26, 103-119. [CrossRef]

60. Rodríguez-Lomba, E.; Molina-López, I.; Suárez-Fernández, R.; Baniandrés-Rodríguez, O. Periarticular Thenar Erythema and Onycholysis Syndrome: A Manifestation of Taxane-Induced Cutaneous Toxicity. Actas Dermosifiliogr. 2017, 108, 595-597. [CrossRef] [PubMed] 
61. Richards, K.N.; Ivan, D.; Rashid, R.M.; Chon, S.Y. Paclitaxel-induced acral erythema. Arch. Dermatol. 2012, 148, 1333-1334. [CrossRef]

62. Kataria, P.S.; Kendre, P.P.; Patel, A.A.; Tahiliani, N.; Bhargav, V.; Parekh, H. Rare occurrence of hand-foot syndrome due to paclitaxel: A rare case report. Indian J. Pharmacol. 2018, 50, 284-286. [PubMed]

63. Grau, J.J.; Caballero, M.; Verger, E.; Monzó, M.; Blanch, J.L. Weekly paclitaxel for platin-resistant stage IV head and neck cancer patients. Acta Otolaryngol. 2009, 129, 1294-1299. [CrossRef]

64. Makrilia, N.; Syrigou, E.; Kaklamanos, I.; Manolopoulos, L.; Saif, M.W. Hypersensitivity reactions associated with platinum antineoplastic agents: A systematic review. Met. Based Drugs 2010, 2010, 207084. [CrossRef] [PubMed]

65. Wiley, K.; Ebanks, G.L.; Shelton, G.; Strelo, J.; Ciccolini, K. Skin Toxicity: Clinical Summary of the ONS Guidelines ${ }^{\mathrm{TM}}$ for Cancer Treatment-Related Skin Toxicity. Clin. J. Oncol. Nurs. 2020, 24, 561-565. [CrossRef]

66. Williams, L.A.; Ginex, P.K.; Ebanks, G.L.; Ganstwig, K.; Ciccolini, K.; Kwong, B.K.; Robison, J.; Shelton, G.; Strelo, J.; Wiley, K.; et al. ONS Guidelines ${ }^{\mathrm{TM}}$ for Cancer Treatment-Related Skin Toxicity. Oncol. Nurs. Forum 2020, 47, 539-556. [CrossRef] [PubMed]

67. Huang, K.-L.; Lin, K.-Y.; Huang, T.-W.; Loh, E.-W.; Hua, Y.-M.; Su, H.-C.; Tam, K.-W. Prophylactic management for taxane-induced nail toxicity: A systematic review and meta-analysis. Eur. J. Cancer Care 2019, 28, e13118. [CrossRef] [PubMed]

68. Di Franco, R.; Calvanese, M.; Murino, P.; Manzo, R.; Guida, C.; Di Gennaro, D.; Anania, C.; Ravo, V. Skin toxicity from external beam radiation therapy in breast cancer patients: Protective effects of Resveratrol, Lycopene, Vitamin $\mathrm{C}$ and anthocianin (Ixor ${ }^{\circledR}$ ). Radiat. Oncol. 2012, 7, 12. [CrossRef] 